\title{
Trends of Using Smart Devices and Web Resources Among Dental Students for Educational Purposes
}

\author{
Muhammad Shehroze Khan ${ }^{2}$, Muhammad Hammad ${ }^{1}$, Urooj Shabbir ${ }^{1}$, Rida Awan ${ }^{2}$, Omer Sefvan Janjua ${ }^{1}$, Malik Muhammad \\ Usama $^{1}$ \\ ${ }^{1}$ Department of Oral and Maxillofacial Surgery, Allied Hospital Faisalabad, Faisalabad, Pakistan \\ ${ }^{2}$ Department of Orthodontics, Allied Hospital Faisalabad, Faisalabad, Pakistan \\ *Correspondence to: Muhammad Hammad, Department of Oral and Maxillofacial Surgery, Allied Hospital Faisalabad, Faisalabad, Pakistan; Email: \\ malikhammad301@gmail.com \\ Received date: October 16, 2020; Accepted date: October 28, 2020; Published date: November 4, 2020 \\ Citation: Khan MS, Hammad M, Shabbir U, et al. (2020) Trends of Using Smart Devices and Web Resources Among Dental Students for Educational Purposes. \\ Advanc Dentistry. 1(1): pp. 1-4. \\ Copyright: (C2020 Khan MS. This is an open-access article distributed under the terms of the Creative Commons Attribution License, which permits unrestricted \\ use, distribution, and reproduction in any medium, provided the original author and source are credited.
}

\section{ABSTRACT}

Introduction: Teaching methods are changing with the social environment and also with the development of information technology. Information technology and internet-connected devices have made learning methods accessible, even during a pandemic that has developed due to COVID19. The learning method should consist of both books and media.

Objectives: The basic aim of this study was to see the trend of usage of smart devices among dental undergraduates and their attitude towards e-learning.

Study Design: Observational cross-sectional study.

Setting: Oral and maxillofacial surgery department, PMC Dental Institute Faisalabad Medical University, Faisalabad.

Materials and Methods: A questionnaire was developed by a team of dental experts and a literature review keeping in mind the trend of internet-connected devices and data was collected on specially designed Performa and submit it to the principal investigator.

Results: The data were collected from 184 participants with a male to female ratio of 1:2.4 and the mean age was 22.5 years. From overall participants $99.5 \%$ have internet access, $97.3 \%$ use smart devices for education purposes and only $41.8 \%$ were comfortable reading e-book. The participants who find mobile phone beneficial are $92 \%$ and $28 \%$ have daily usage of more than 6 -hours. When faced with a challenging scenario $23 \%$ said that they web resources and occasionally consult health-related videos.

Conclusion: Within the limits of this study we concluded that students find usage of smart devices and the internet beneficial for study purposes and therefore, the study methods should consist of both books and media.

\section{Keywords:}

Smart devices, Internet, Information technology, Dental students

\section{Introduction}

Teaching methods must adapt to the ever-changing social environment. Information and communication technology has played a vital role in learning and higher education over the last few decades and the use of mobile/ internet-connected devices in daily tasks as well as within educational and professional environments is witnessing the use of information and communication technology [1]. It is striking that students make use of mobile phones while attending university courses. The use of smartphones in daily life by medical students and faculty is almost $85 \%$ and they also look forward to increasing usage of mobile phones in medical education and daily practice.

Currently, medical students have grown up in the age of information technology and they are vastly surrounded by it. All those born after the 1980s are surrounded by mobile technology and social media and are getting notable benefits from it. The trend of using smart devices has enhanced blended learning with the potential for improving campus learning if allowed within the premises [2].

Dental students must be skilled in the use of information technology and web resources for the acquisition of evidencebased information and to communicate with the patients remotely while managing their records electronically at the same time. Nearly half of the dental graduates want to go for private practice which means they must be adept at utilizing practice management and accounting software applications [3]. The use of smart devices like computer, mobile phones, and tablets can improve the learning environments and can help us for remote learning as well [4], especially in challenging situations like the novel coronavirus where the normal study routines for lectures and group study at campus premises does not seem possible. Dentistry-related applications are becoming very popular nowadays yet there are limited data from studies available on the usage of mobile phones and web resources by dental students. The most important factor that supports the use of smart devices and web resources among dental students is the easy availability of the internet that has taken possibilities to another level. Studies have proven that learning can be 
improved by both words and images, rather than words alone. The methodology of using technology in the classroom is not implemented worldwide. The wide use of technology is likely to increase access to problem-based solutions, information evaluation, and creative thinking. The traditional method of learning is by recalling the contents of the lesson and pays less attention to actual learning which causes the dental students to be incompetent while coming into contact with systemic patients, putting their status and repute at risk due to an undesirable performance [5]. The process of learning could be anywhere and anytime enabling the students to use smart devices and web resources for learning and minimizing their deficiencies [6]. Medical students mostly use software that is related to diagnosis, treatment planning, and drug usage leading to an increased demand for educational software based on decision making during clinical scenarios $[7,8]$. Several videos and online lectures are available on YouTube and other sites that are providing knowledge to the students especially in a pandemic state that has recently been developed due to COVID-19.

The ongoing study aimed to analyze the trend of using smart devices and web resources among dental undergraduate students and their attitudes and opinions towards e-learning in terms of various variables.

\section{Materials and Methods}

After seeking approval from ERC, The Observational crosssectional study was conducted in the department of Oral and Maxillofacial surgery, Allied Hospital Faisalabad, the study was conducted in January 2020. Dental students of Allied hospital Faisalabad were recruited in the study. After a thorough literature review and with the help of a team of dental experts, the questionnaire was developed on Google docs and data collected. To evaluate different perspectives related to the usage of smart devices and web resources, different questions were asked in the questionnaire. The participants were asked to fill the Performa and submit it to the principal investigator while maintaining participants' confidentiality. The interpretation of the data was done by using SPSS 20.0 version.

\section{Results}

The data was collected from 184 participants out of which 54 were male and 130 females giving a male to female ratio of $1: 2.4$. The mean age of the participants is 22.55 years. There were a total of fourteen(14) questions in the questionnaire, some of which were single checkpoints and some were of multiple checkpoints. The frequencies and percentages of the responses is given in Table 1.

Figure 1 shown below depicts the responsiveness to the question "On average how much time do you spend on the internet daily?" The majority of the subjects agreed to spend more than 6 hours daily on the internet. The dental students who consider the use of web resources and smart devices beneficial for educational purposes are given below in Figure 2. On asking "how often you access health-related videos for learning purposes and the responses they submitted are given in Figure 3.

Table 1: Showing frequency and percentages of the responses by the dental students.

\begin{tabular}{|l|l|l|l|l|}
\hline Questions & \multicolumn{2}{l|}{ Frequencies } & \multicolumn{2}{l|}{ Percentages } \\
\cline { 2 - 5 } & Yes & No & Yes & No \\
\hline Do you have access to internet on your smart device? & 183 & 1 & 0.995 & 0.005 \\
\hline Do you use a smart device for educational purpose? & 179 & 5 & 0.973 & 0.027 \\
\hline Do you use social networking sites for educational discussion? & 127 & 57 & 0.69 & 0.31 \\
\hline Do you feel comfortable reading an E-Book on your smart device? & 77 & 107 & 0.418 & 0.582 \\
\hline
\end{tabular}

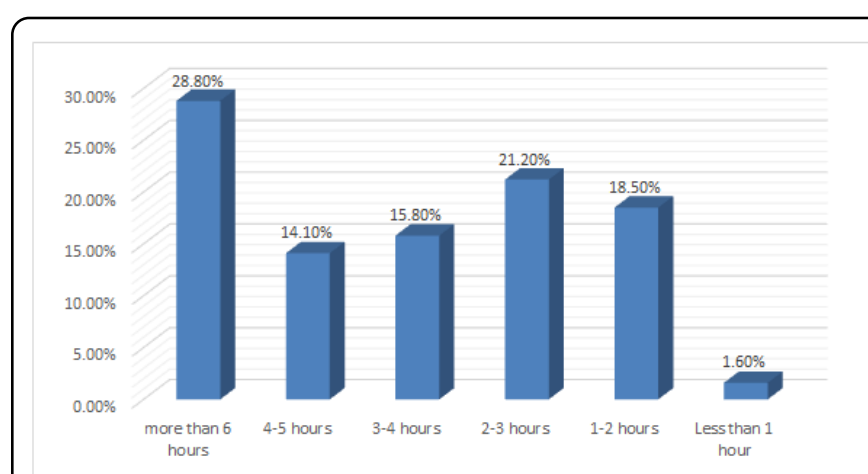

Figure 1: Showing percentages of the time they spend on internet dai.

When facing a challenging scenario $48.4 \%$ voted for consulting seniors, $23.4 \%$ said that they use web resources $15.2 \%$ reviewed books and $12.5 \%$ said they get an opinion from peers/ colleagues as shown in Figure 4. As the process of learning can be anywhere and from anyone. On inquiring, 39.1\% said that they learn most from books, 32.1 agreed that they learn from interactive sessions, the learning from lectures is $13 \%$, from

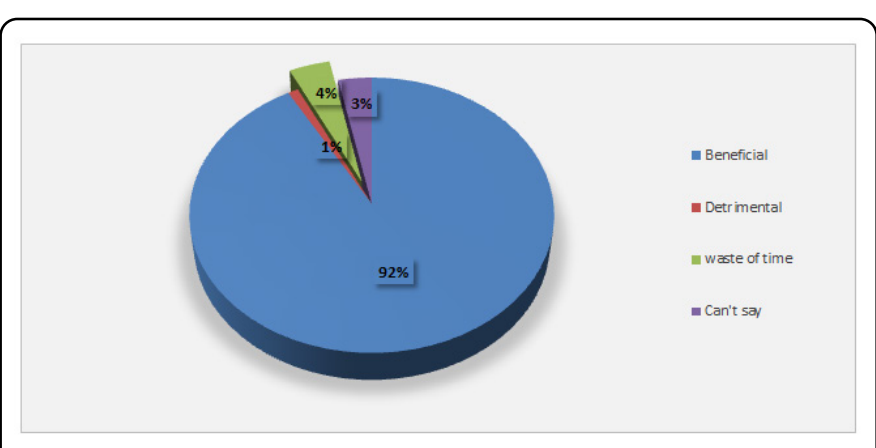

Figure 2: Showing percentages of benfecial effects of smart devices daily.

colleagues is $7.1 \%$ while 8.7 said that they learn from websites as shown in Figure 5 . The students who said that the learning method should include both media and books are $91.3 \%$ as shown in Figure 6.

\section{Discussion}

The results of this study show that most of the dental students own smart devices and most of them use smartphones as a 


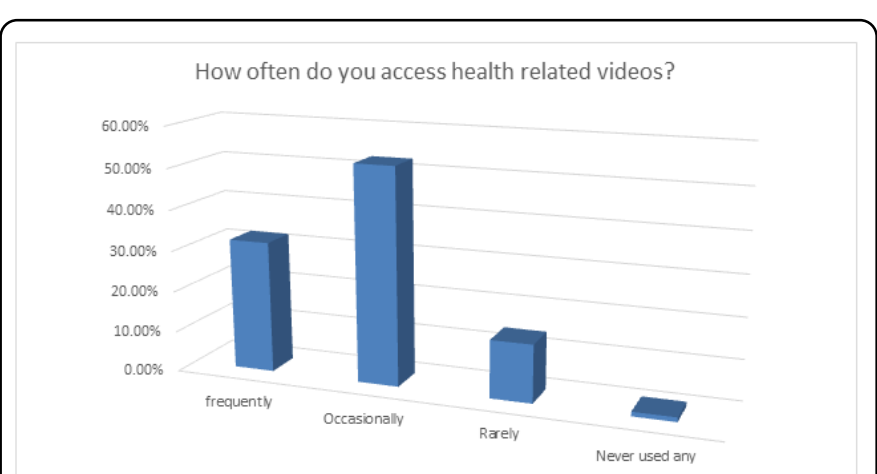

Figure 3: Showing results for consultation of health-related videos.

when faced a challenging scenario, who/what would you like to consult?

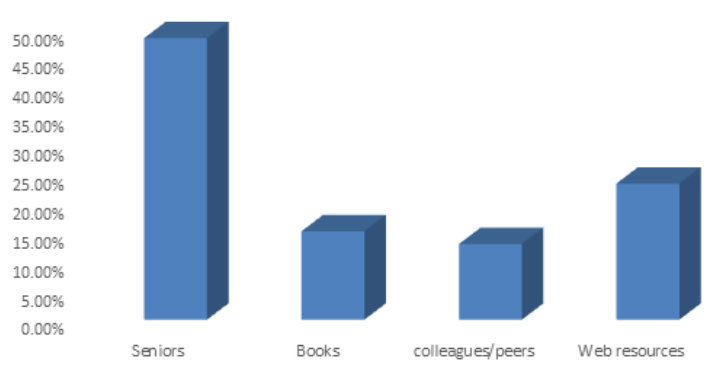

Figure 4: Showing results of consultation when faced a challenging scenario.

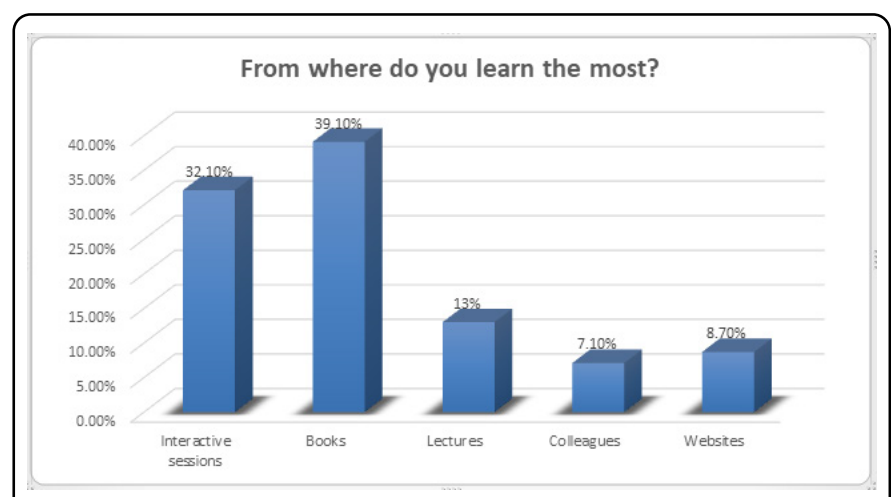

Figure 5: Showing results for learning method should include.

IN YOU OPINION LEARNING METHOD SHOULD INCLUDE?

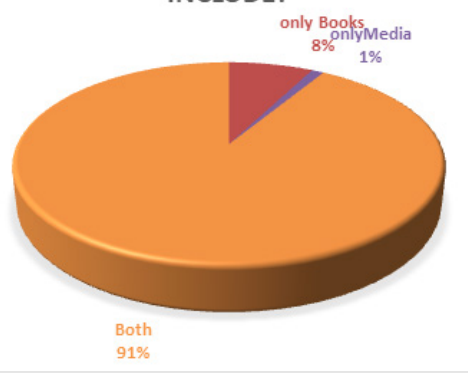

Figure 6: Showing results in the learning method should include.

learning tool that allows students to access a learning resource. Most of the dental students have reliable internet connectivity which makes learning resources available to them without having the need to physically visit the libraries, desktop computers, and meeting with colleagues. The use of smart devices has been steadily increasing in the medical field and with the development of medical-related applications almost every health practitioner is benefiting from it [11].

In this study, dental students who said that they have internet connection on their smart devices are $99.5 \%$. This is in agreement with the study conducted by Santosh Kumar et al that most dental students use means of internet for accessing information and they have internet access $[10,11]$. On further intriguing, we found that $97.3 \%$ use smartphones for educational purposes, and only $41.8 \%$ said that they feel comfortable reading e-books using smartphones [12].

In another question, $69 \%$ of the participants said that they use social networking sites for education and discussion purposes which are also cited by Asli suner et al. in his study that students use social networking sites for their discussion purposes and to help each other for their daily tasks. The majority of the students said that they spend an average of more than 5 hours daily on the internet [13]. Nowadays everything is available on the internet so $92 \%$ of participants said that they find smart devices beneficial for their study purposes and a comprehensive review has been given in the study conducted by Rung et al. that most of the Australian dental students found the smart devices as a beneficial tool for their study purposes [1].

The results of this study also stated that $31 \%$ of the contributors frequently access health-related videos that help them tackle some challenging scenarios. Hurtubise $L$ et al also mentioned in his study that health-related videos are very useful not only for medical students but also for other faculty members' too [14]. When facing a challenging scenario $48.4 \%$ of the dental students said that they would like to consult some seniors in that case rather than to consult books and web resources [15]. Apart from the widespread usage of smart devices, $39.1 \%$ of the participants said that they learn most from books while $8.7 \%$ opted for websites, $32.1 \%$ said that they learn more from interactive sessions and $7.1 \%$ mentioned learning from colleagues. The knowledge of dental students is based on theory and clinical so $91 \%$ of the participants said that the learning method should include both books and media as this helps them in recalling knowledge when facing a challenging scenario during clinical practice in professional life. The study conducted by Lucinda Wynter et al. also stated that medical students learn more when using a combination of both books and media as compared to the traditional method of using books alone [16].

The limitation of this study is that we have collected data from one institution hence ignoring trends of teaching methods followed by other institutions.

\section{Conclusion}

Within the limits of this study, we conclude that most dental students find the use of smart devices and web resources beneficial as this reduces their hassle to consult multiple books. They access different health-related videos to create photogenic memory and also helps them to recall things easily during clinical practice. The traditional method of study is still ongoing in our county and higher authorities should try to 
improve the teaching methods hence promoting smart and efficient learning methods blending the use of both media and books. Based on the results of this study, I would like to recommend a teaching method consisting of both books and media.

\section{Conflict Of Interest}

None declared

\section{References}

1. Rung A, Warnke F, Mattheos N (2014) Investigating the use of smartphones for learning purposes by Australian dental students. JMIR M health Uhealth 2(2): pp. 20.

2. Scarbecz M, DeSchepper EJ (2018) Trends in first-year dental students' information technology knowledge and use: results from a U.S. dental school in 2009, 2012, and 2017. Journal of Dental Education 82(12): pp. 1287-1295.

3. Nazir MA, Izhar F, Tariq K, et al. (2018) A cross-sectional study of dentists about the need for a practice management course in undergraduate dental program. Eur J Dent 12(4): pp. 508-515.

4. Ventola $\mathrm{CL}(2014)$ Social media and health care professionals: benefits, risks, and best practices. J Clin Pharm Ther 39(7): pp. 491-499.

5. Nourian A, Nourian A, Ebnahmadi A, et al. (2012) Comparison of e-learning and traditional classroom instruction of dental public health for Dental Students of Shahid Beheshti Dental School during 2010-2011. J Dent Sch 30(3): pp.174-183.

6. Manakil J, George R (2017) Mobile learning practices and preferences a way forward in enhancing dental education learning experience. Eur J Gen Dent 2(6): pp. 22-28.

7. Duncan V, Vokey S, Gordon S, et al. (2015) Mobile device use in pharmacy: a multi-institutional study. J Can Health Libr Assoc
36(3): pp. 106-113.

8. Boruff JT, Storie D (2014) Mobile devices in medicine: a survey of how medical students, residents, and faculty use smartphones and other mobile devices to find information. J Med Libr Assoc 102(1): pp. 22-30.

9. Apuke OD, Lyendo TO (2018) University students' usage of the internet resources for research and learning: forms of access and perceptions of utility. Journal of Heliyon 4(1): e01052.

10. Kumar S, Tadakamadla J, Tibdewal H, et al. (2010) Internet usage among undergraduate dental students in India. Journal of Rev. odonto ciênc 25(3): pp. 261-265.

11. Boruff JT, Storie D (2014) Mobile devices in medicine: a survey of how medical students, residents, and faculty use smartphones and other mobile devices to find information. J Med Libr Assoc 102(1): pp. 22-30

12. Khatoon B, Hill K, Walmsley AD (2019) Mobile learning in dentistry: challenges and opportunities. Br Dent J 227 (4): pp. 298-304.

13. Suner A, Yilmaz Y, Piskin B (2019) Mobile learning in dentistry: usage habits, attitudes and perceptions of undergraduate students. PeerJ 7(1): pp.73-91.

14. Hurtubise L, Martin B, Gilliland A (2013) Mahan J. To play or not to play: leveraging video in medical education. J Grad Med Educ 5(1): pp. 13-18.

15. Lee $H$, Hahm M, Lee SG (2018) Undergraduate medical students perceptions and intentions regarding patient safety during clinical clerkship. BMC Med Edu 18(1): pp. 66.

16. Wynter L, Burgess A, Kalman E, et al. (2019) Medical students: what educational resources are they using?. BMC Med Educ pp 19(1): pp. 36. 